\title{
KAJIAN PEDOMAN PENATAUSAHAAN HASIL HUTAN DI HUTAN RAKYAT SEBAGAI DASAR ACUAN PEMANFAATAN HUTAN RAKYAT
}

\author{
STUDY ON FOREST PRODUCT ADMINISTRATION ORIENTATION IN COMMUNITY \\ FOREST AS A BASIC REFERENCE IN COMMUNITY FOREST US AGE
}

Oleh/By:

Epi Syahadat

\begin{abstract}
Forest product administration in community forest is not in good and proper arrange and it's implementation can not sustain the forest and collect the optimum forest product revenue. The study was conducted on forest product administration of community forest aiming the policy weeknesses and ineffectiveness of timber administration. The study is conducted by reviewing timber administration policy in community forest.

The study result showed that there are intent in the timber administration regulation from community forest which should be revined in order to encourage the sustain ability of community forest. Reviewed should be made to simplified the regulation, starting from cutting permit to the transporting permit.
\end{abstract}

Key word : community forest, forest product administration, transportation.

\section{ABSTRAK}

Penatausahaan hasil hutan di hutan rakyat belum tertata dengan baik dan pelaksanaannya oleh petugas atau oleh instansi di daerah asal dan tujuan peredaran kayu masih belum mampu menjamin kelestarian hutan dan penerimaan negara atas hasil hutan secara optimal. Kajian penatausahaan hasil hutan pada hutan rakyat dilakukan untuk mengetahui kelemahan kebijakan dan pelaksanaan penatausahaan hasil hutan yang menyebabkan tidak efektif mengendalikan peredaran kayu. Kajian dilakukan dengan melakukan review kebijakan penatausahaan hasil hutan yang ada, khususnya kebijakan penatausahaan hasil hutan di hutan rakyat.

Hasil kajian menunjukkan bahwa masih banyak hal yang perlu disempurnakan dalam aturan penatausahaan hasil hutan di hutan rakyat agar ketertiban, kelancaran, dan tanggung jawab dalam pengelolaan hutan rakyat dapat tercipta dengan baik. Penyempurnaan mulai dari pembuatan Surat Izin Penebangan (SIP) serta perlu adanya berita acara pemeriksaan penebangan sebelum pengesahan LHP, sampai kepada pengangkutan hasil hutan perlu disederhanakan tanpa mengurangi fungsi penatausahaan hasil hutan yang efektif dalam melestarikan hutan dan mejamin hak-hak negara atas hasil hutan.

Kata kunci : hutan rakyat, penatausahaan hasil hutan, pemanfaatan, peredaran, pengangkutan.

\section{PENDAHULUAN}

Potensi hutan alam sebagai penghasil kayu bagi pembangunan nasional semakin hari semakin menurun, di sisi lain permintaan kayu terutama sebagai bahan baku industri pengolahan kayu makin bertambah. Salah satu alternatif untuk memenuhi kebutuhan tersebut melalui pengembangan hutan rakyat. Disamping mempunyai fungsi pendukung lingkungan, konservasi tanah dan perlindungan tata air, hutan rakyat atau lahan-lahan lain diluar kawasan hutan juga mempunyai kontribusi yang cukup besar dalam upaya pemenuhan kebutuhan bahan baku kayu yang dihasilkan dari luar kawasan hutan milik negara.

Mengingat bahwa kayu rakyat adalah hasil hutan yang diperoleh dari lahan milik sendiri, maka pengolahan dan pemanfaatan hasil hutan sepenuhnya menjadi hak pemilik, sedangkan fungsi pemerintah dalam hal ini hanya melakukan pembinaan untuk menjamin kelestarian hutan dan melindungi kelancaran peredaran hasil hutan melalui penatausahaan hasil hutan (Anonim, 2002). Dalam upaya menjamin kelestarian hutan rakyat, maka pengaturan atau penatausahaan hasil hutan di hutan rakyat menjadi satu hal penting yang perlu diperhatikan. Oleh karena itu untuk kelancaran serta ketertiban dalam pengelolaan dan pelaksanaan penatausahaan hasil hutan di hutan rakyat dipandang perlu dibuatkan suatu dasar acuan atau petunjuk pelaksanaannya (Juklak)

Petunjuk pelaksanaan (juklak) penatausahaan hasil hutan di hutan rakyat dimaksudkan sebagai dasar acuan dalam penertiban pemanfaatan hasil hutan di hutan rakyat, atau dengan perkataan lain 
merupakan dasar acuan pelaksanaan penatausahaan hasil hutan bagi pemerintah Kabupaten/Kota dan aparat pelaksana di lapangan dalam menyelenggarakan penatausahaan hutan rakyat. Ketentuan yang mengatur penatausahaan hasil hutan di hutan rakyat hingga kini belum di atur secara khusus, meskipun diakui bahwa fungsi dan peranan kayu rakyat cukup penting. Fungsi hutan rakyat ada 3 (tiga), yaitu : a. Fungsi Konservasi, b. Fungsi Lindung, dan c. Fungsi Produksi. Sedangkan pemanfaatan hutan rakyat yang berfungsi produksi dapat berupa : a. Pemanfaatan hasil hutan kayu, b. Pemanfaatan hasil hutan bukan kayu, dan c. Pemanfaatan jasa lingkungan (Anonim, 2005).

Adapun tujuan kajian ini, adalah :

1 Dengan dibuatkannya petunjuk pelaksanaan penatausahaan hasil hutan di hutan rakyat diharapkan adanya keseragaman dalam pemanfaatan hasil hutan rakyat.

2 Terselanggaranya penatausahaan hasil hutan rakyat yang sederhana, tertib, lancar sesuai dengan perkembangan otonomi daerah.

Sasarannya, adalah :

1 Pengamanan terhadap berbagai kepentingan negara, seperti kelestarian hutan, melindungi hak-hak negara atas hasil hutan di hutan rakyat.

2 Menciptakan penatausahaan hasil hutan di hutan rakyat yang tertib, lancar, efisien dan bertanggung jawab.

3 Termonitornya informasi kualitatif dan kuantitatif mengenai kayu rakyat sebagai bahan untuk menyusun kebijakan lebih lanjut.

Ruang Lingkup penelitian pemanfaatan hasil hutan di hutan rakyat meliputi semua hasil hutan berupa kayu yang berasal dan diproduksi dari luar kawasan hutan seperti hutan milik, hutan rakyat, tegalan, kebun atau kawasan perkebunan.

\section{METODE PENELITIAN}

\section{A. Kerangka Pemikiran}

Kayu rakyat merupakan salah satu komoditas yang memberikan pendapatan bagi masyarakat dan mempunyai kontribusi yang cukup besar dalam upaya pemenuhan bahan baku industri kayu dan rumah tangga. Dalam Perarturan Menteri Kehutanan Nomor P.26/2005, tentang Pedoman Pemanfaatan Hutan Hak/Rakyat, pasal 12 ayat (1) dinyatakan pemanfaatan hutan hak dilakukan oleh pemegang hak atas tanah yang bersangkutan sesuai dengan fungsinya. Dalam ayat (2) dinyatakan pemanfaatan hutan hak sebagaimana dimaksud pada ayat (1), bertujuan untuk memperoleh manfaat yang optimal bagi pemegang hak dengan tidak mengurangi fungsinya. Oleh karena itu untuk mencegah kerusakan hutan negara yang kian memprihatinkan akibat perambahan, penjarahan, penebangan liar dan sebagai pengaman dan pengendalian peredaran kayu rakyat di lintas Kabupaten, maka dipandang perlu untuk membuat petunjuk pelaksanaan penatausahaan hasil hutan di hutan rakyat. Apabila digambarkan mekanisme kerangka pemikirannya, adalah sebagai berikut: 


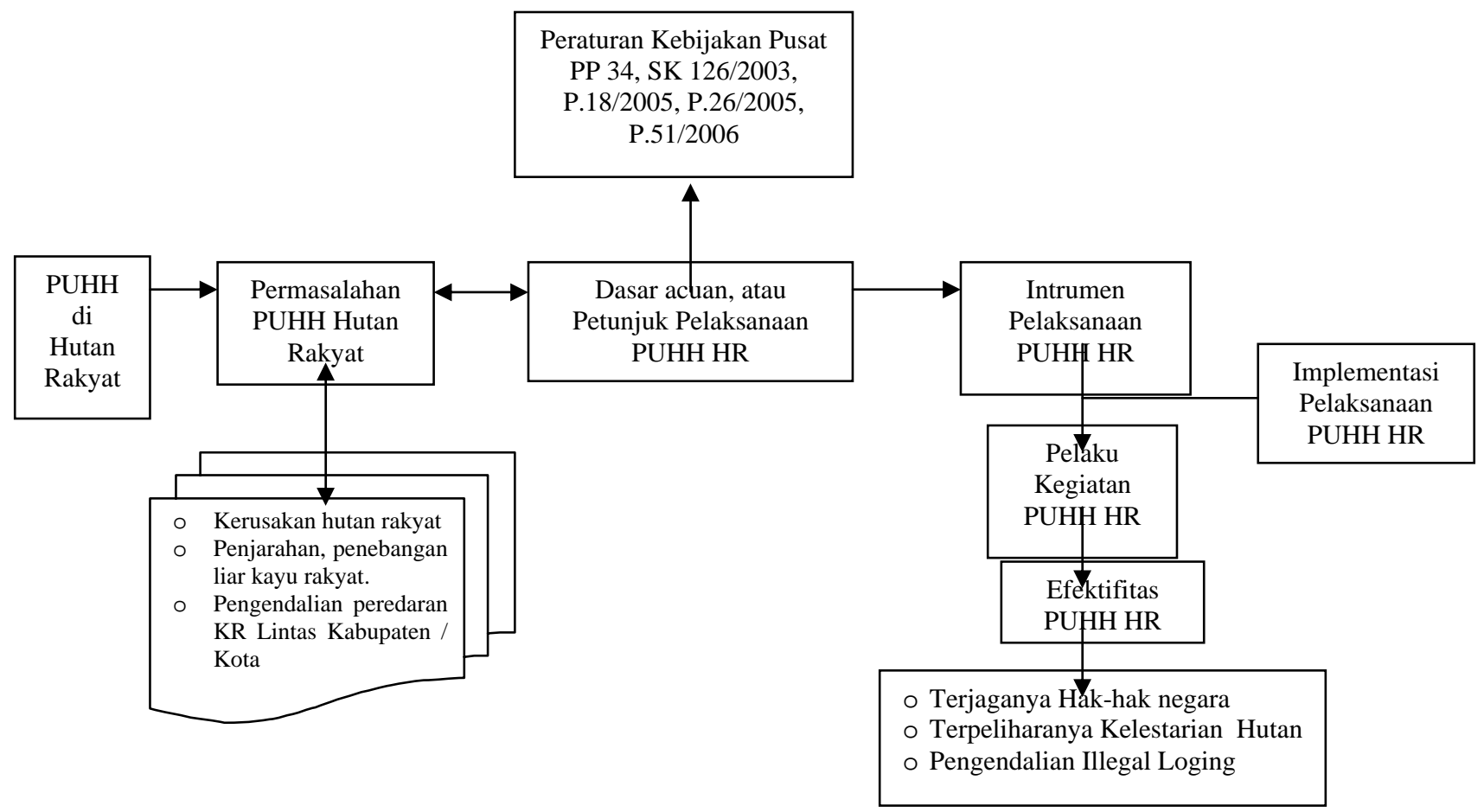

\section{B. Pengumpulan Data dan Referensi.}

Data yang dikumpulkan adalah data primer, dan data sekunder. Data primer diperoleh melalui pengamatan dan wawancara dengan Pejabat Kehutanan di daerah dan Badan Usaha yang melakukan kegiatan pengelolaan hasil hutan. Data yang diperoleh seperti pelaksanaan penatausahaan kayu rakyat, kesenjangan pelaksanaan dan uraian tugas, pengeluaran perusahaan dalam pengurusan ijin, pengesahan dan penerbitan dokumen penatausahaan hasil hutan. Data sekunder diperoleh di kantor kehutanan, perusahaan, dan perpustakaan seperti potensi hutan rakyat (luasan hutan rakyat, potensi tegakan), realisasi produksi kayu bulat.

Referensi pemanfaatan hasil hutan di hutan rakyat, adalah sebagai berikut:

a. Peraturan Pemerintah Republik Indonesia Nomor 34, tahun 2002, tentang Tata Hutan dan Penyusunan Rencana Pengelolaan Hutan, Pemanfaatan dan Penggunaan Kawasan Hutan.

b. Surat Keputusan Menteri Kehutanan Nomor 126/Kpts-II/2003, tentang Penatausahaan Hasil Hutan.

c. Peraturan Menteri Kehutanan Nomor P.18/Menhut-II/2005, tentang Perubahan Ketiga Atas Keputusan Menteri Kehutanan Nomor 126/Kpts-II/2003, tentang Penatausahaan Hasil Hutan.

d. Peraturan Menteri Kehutanan Nomor P.26/Menhut-II/2005, tentang Pedoman Pemanfaatan Hutan Hak/Rakyat.

e. Peraturan Menteri Kehutanan Nomor P.51/Menhut-II/2006, tentang Penggunaan Surat Keterangan Asal Usul (SKAU) Untuk Pengangkutan Hasil Hutan Kayu Yang Berasal Dari Hutan Hak.

\section{Metode Analisis}

Dalam penelitian ini, metode analisis yang digunakan adalah metode analisis deskriptif, dimana dalam mengkaji usulan pedoman pemanfaatan hasil hutan di hutan rakyat, dilihat dari berbagai perundang-undangan yang berkaitan dengan dasar pembuatannya atau payung hukumnya yang disesuaikan dengan Peraturan Menteri Kehutanan Nomor P.26/Menhut-II/2005, Peraturan Pemerintah Nomor 34, tahun 2002, SK Menteri Kehutanan No 126/Kpts-II/2003, Peraturan Menteri Kehutanan No P.18/Menhut-II/2005, dan Peraturan Menteri Kehutanan Nomor P.51/Menhut-II/2006 


\section{HASIL DAN PEMBAHASAN}

\section{A. Gambaran Umum dan Potensi Hutan Rakyat}

1 Potensi Hutan Rakyat

Luas hutan rakyat di Indonesia, adalah 1.271.505,61 ha, dengan jumlah perkiraan tegakan sebanyak 42.965.519 pohon, pada Tabel 1 di bawah dapat dilihat, bahwa Jawa Tengah mempunyai lahan hutan rakyat yang terluas, yaitu 198.790,02 $\mathrm{Ha}$ atau 15,63 \% dengan perkiraan potensi tegakan sebanyak 12.557 .702 pohon atau 29,23\%. Adapun jenis tanaman yang paling banyak ditanam di hutan rakyat, diantaranya adalah : Sengon (albiria falcataria), Mahoni (swietenia macrophylla), Jati (tectona grandis), Akasia (acacia mangium), Sonokeling (dalbergia latifolia), Pete (parkia speciosa), Nangka (artocarpus integra), Gamal (inocarpus edulis), Mindi (melia azadararah), Cemara (causuarina equisetifdia), Suren (toona sureni), Mangga (mangifera indica), Melinjo (gnetum gnemon), Kelapa (cocos nicifera), Kemiri (aleurites moluccana), Pinang (casearia coriacea), Mete (daemonorops niger), Rambutan (nephelium lappaceum), Durian (durio ziberthinus), Bambu (gigancocbloa apus), Sungkai (beterophrogma macrolobum), Karet (ficus elastica), Kopi (abelmoschus esculentus), Kapuk (ceiba pentandra), Ampupu (ecalyptus urophylla), Johar (cassia siamea), Cempedak (artocarpus champeden), Angsana (pterocarpus indica), Nyatoh (palaquium javense), Enau (arenga pinnata), Asam (tamarindus indica), Kaliandra (calliandra calotbygisus), Matoa (pometia pinnata) dan Sonokrit (dalbergia sisso).

Tabel 1 Luas Lahan Hutan Rakyat Dan Potensi Tegakan Kayu Rakyat Di Indonesia Sampai Dengan April 2006

Table 1 The Area And Estimating Number of Trees Of Community Forest In Indonesia Untill April 2006

\begin{tabular}{|c|c|c|c|c|c|}
\hline $\begin{array}{c}\text { No/ } \\
\text { No }\end{array}$ & $\begin{array}{l}\text { Propinsi / } \\
\text { Province }\end{array}$ & $\begin{array}{l}\text { Luas Hutan } \\
\text { Rakyat / Area Of } \\
\text { Community Forest } \\
\text { (Ha) }\end{array}$ & $\%$ & $\begin{array}{c}\text { Perkiraan Potensi } \\
\text { Tegakan / } \\
\text { Estimating Total } \\
\text { Trees (Pohon/ } \\
\text { trees) }\end{array}$ & $\%$ \\
\hline 1 & Jawa Barat & $79.056,06$ & 6,22 & $4.457 .327,47$ & 10,37 \\
\hline 2 & Jawa Tengah & $198.790,02$ & 15,63 & $12.557 .702,11$ & 29,23 \\
\hline 3 & Jawa Timur & $93.561,23$ & 7,36 & $4.978 .835,87$ & 11,59 \\
\hline 4 & DI Yogyakarta & $29.039,00$ & 2,28 & $1.447 .826,00$ & 3,37 \\
\hline 5 & Jakarta & 00 & 0 & 00 & 0 \\
\hline 6 & Aceh & $11.040,00$ & 0,87 & $38.544,22$ & 0,09 \\
\hline 7 & Sumatera Utara & $84.827,00$ & 6,67 & $1.777 .683,00$ & 4,14 \\
\hline 8 & Sumatera Barat & $41.697,20$ & 3,28 & $67.927,00$ & 0,16 \\
\hline 9 & Riau & $14.613,06$ & 1,15 & $1.757 .875,00$ & 4,09 \\
\hline 10 & Jambi & $11.047,38$ & 0,87 & $8.893,38$ & 0,02 \\
\hline 11 & Sumatera Selatan & $55.443,95$ & 4,36 & $1.472 .345,00$ & 3,43 \\
\hline 12 & Bengkulu & $1.650,00$ & 0,13 & 00 & 0 \\
\hline 13 & Lampung & $10.308,00$ & 0,81 & 00 & 0 \\
\hline 14 & Bali & $13.397,50$ & 1,05 & $362.295,20$ & 0,84 \\
\hline 15 & $\begin{array}{ll}\text { Nusa } & \text { Tenggara } \\
\text { Timur } & \end{array}$ & $150.600,00$ & 11,84 & $3.190 .613,55$ & 7,43 \\
\hline 16 & $\begin{array}{ll}\text { Nusa } & \text { Tenggara } \\
\text { Barat } & \end{array}$ & $51.834,66$ & 4,08 & $1.014 .595,00$ & 2,36 \\
\hline 17 & Kalimantan Selatan & $136.263,00$ & 10,72 & $3.885 .764,00$ & 9,04 \\
\hline 18 & Kalimantan Timur & $9.074,00$ & 0,71 & 00 & 0 \\
\hline 19 & $\begin{array}{l}\text { Kalimantan } \\
\text { Tengah }\end{array}$ & $13.359,00$ & 1,05 & 00 & 0 \\
\hline 20 & Kalimantan Barat & $4.419,00$ & 0,35 & 00 & 0 \\
\hline 21 & Sulawesi Utara & $24.539,00$ & 1,93 & $112.338,66$ & 0,26 \\
\hline 22 & Sulawesi Tengah & $27.693,55$ & 2,18 & $441.745,35$ & 1,03 \\
\hline 23 & Sulawesi Selatan & $149.060,00$ & 11,72 & $5.393 .209,00$ & 12,55 \\
\hline 24 & Sulawesi Tenggara & $20.625,00$ & 1,62 & 00 & 0 \\
\hline 25 & Maluku & $3.558,00$ & 0,28 & 00 & 0 \\
\hline
\end{tabular}




\begin{tabular}{|l|l|r|r|r|c|}
\hline 26 & Papua & $36.010,00$ & 2,83 & 00 & 0 \\
\hline & Jumlah / Total & $1.271 .505,61$ & 100 & $42.965 .519,81$ & 100 \\
\hline & Rata-rata / Average & $48.904,06$ & & $1.652 .519,99$ & \\
\hline
\end{tabular}

Sumber / Source : Direktorat Jenderal RLPS, 2006.

2 Realisasi Produk Kayu Bulat

Pada Tabel 2 di bawah dapat dilihat perkembangan realisasi produk kayu bulat dari hutan rakyat dari tahun $1999 \mathrm{~s} / \mathrm{d}$ tahun 2003. Pada tahun 1999/2000, yaitu sebanyak 895.371 M³ atau 4,34 $\%$ dari jumlah realisasi produk kayu bulat pada periode tahun tersebut, sedangkan pada tahun 2003 produk kayu bulat dari hutan rakyat menurun hanya $59.538 \mathrm{M}^{3}$ atau sebesar $0,59 \%$ dari jumlah realisasi produk kayu bulat pada tahun tersebut.

Tabel 2 Realisasi Produksi Kayu Bulat dari Tahun 1999 - 2003

Table 2 Wood Product 1999 Up To 2003

\begin{tabular}{|c|l|r|r|r|r|r|}
\hline \multirow{N}{*}{$\begin{array}{l}\text { Asal Kayu } \\
\text { Wood } \\
\text { Source }\end{array}$} & $\begin{array}{c}1999 / 2000 \\
\left(\mathrm{M}^{3} / \mathrm{Cu} \mathrm{M}\right)\end{array}$ & $\begin{array}{c}2000 *) \\
\left(\mathrm{M}^{3} / \mathrm{Cu} \mathrm{M}\right)\end{array}$ & $\begin{array}{c}2001 \\
\left(\mathrm{M}^{3} / \mathrm{Cu} \mathrm{M}\right)\end{array}$ & $\begin{array}{c}2002 \\
\left(\mathrm{M}^{3} / \mathrm{Cu} \mathrm{M}\right)\end{array}$ & $\begin{array}{c}2003 \\
\left(\mathrm{M}^{3} / \mathrm{Cu} \mathrm{M}\right)\end{array}$ \\
\hline 1 & $\begin{array}{l}\text { RKT } \\
\text { Hutan } \\
\text { Alam }\end{array}$ & $10.373 .932,00$ & $3.450 .133,00$ & $1.809 .099,00$ & $3.019 .839,00$ & $3.652 .335,00$ \\
\hline 2 & $\begin{array}{l}\text { Perum } \\
\text { Perhutani }\end{array}$ & $1.890 .900,00$ & $1.511 .000,00$ & $1.455 .403,00$ & $1.559 .026,00$ & $976.806,00$ \\
\hline 3 & $\begin{array}{l}\text { Hutan } \\
\text { Tanaman }\end{array}$ & $2.974 .101,00$ & $5.783 .514,00$ & $5.918 .766,00$ & $4.933 .756,00$ & $4441.065,00$ \\
\hline 4 & $\begin{array}{l}\text { Hutan } \\
\text { Rakyat }\end{array}$ & $895.371,00$ & $488.910,00$ & 00 & 00 & $59.538,00$ \\
\hline 5 & IPK & $7.271 .907,00$ & $4.564 .591,00$ & $2.323 .614,00$ & $182.708,00$ & $956.471,00$ \\
\hline & $\begin{array}{l}\text { Jumlah / } \\
\text { Total }\end{array}$ & $20.619 .940,00$ & $13.798 .535,00$ & $10.051 .479,00$ & $8.136 .303,00$ & $10.086 .217,00$ \\
\hline & $\begin{array}{l}\text { Rata-rata } \\
\text { / Average }\end{array}$ & $4.123 .988,00$ & $2.759 .707,00$ & $2.010 .295,80$ & $1.627 .260,60$ & $201.7243,40$ \\
\hline
\end{tabular}

Sumber / Source: Proceeding Seminar, Strategies for Development of Sustainable Wood-Based Industries Indonesia, ITTO 2004.

3 Perkiraan Pasokan Kayu Bulat

Pada Tabel 3 di bawah, dapat dilihat bahwa pada tahun 2004, kayu yang berasal dari hutan rakyat dapat memasok untuk bahan baku industri kayu, sebanyak 10,7 juta $\mathrm{M}^{3}$ atau sebesar 25,30\% dari jumlah perkiraan pasokan kayu bulat.

Tabel 3 Perkiraan Pasokan Kayu Bulat Tahun 2004

Table 3 Estimation Wood Log's Year 2004

\begin{tabular}{|c|c|c|c|c|c|c|c|}
\hline \multicolumn{8}{|c|}{ (Dalam Jutaan / In Million } \\
\hline No & $\begin{array}{c}\text { Sumber / } \\
\text { Source }\end{array}$ & $\begin{array}{c}\text { Jumlah } \\
\text { Total }\left(\mathrm{M}^{3}\right. \\
\text { / Cu } M)\end{array}$ & $\%$ & No & $\begin{array}{l}\text { Produk / } \\
\text { Product }\end{array}$ & $\begin{array}{c}\text { Jumlah / } \\
\text { Total } M^{3} \\
\text { / Cu } M)\end{array}$ & $\%$ \\
\hline 1 & Hutan Alam & 5,7 & 13,48 & 1 & Plywood & 9,27 & 23,92 \\
\hline 2 & $\begin{array}{l}\text { Hutan } \\
\text { Tanaman }\end{array}$ & 15,6 & 36,88 & 2 & Sawn Timber & 7,24 & 18,68 \\
\hline 3 & Hutan Rakyat & 10,7 & 25,30 & 3 & $\begin{array}{l}\text { Wood } \\
\text { Working }\end{array}$ & 1,75 & 4,79 \\
\hline 4 & Kebun & 7,5 & 17,73 & 4 & Pulp & 20,39 & 52,61 \\
\hline 5 & $\begin{array}{l}\text { Perum } \\
\text { Perhutani }\end{array}$ & 0,8 & 1,89 & & & & \\
\hline 6 & Impor & 2,0 & 4,73 & & & & \\
\hline 7 & IPK / APL & 00 & 0 & & & & \\
\hline & Jumlah / Total & 42,3 & 100 & & & 38,76 & 100 \\
\hline
\end{tabular}




\begin{tabular}{|l|l|c|c|c|c|c|c|}
\hline & $\begin{array}{l}\text { Rata-rata / } \\
\text { Average }\end{array}$ & 6,04 & & & & 9,69 & \\
\hline
\end{tabular}

Sumber/ Source : Anonim, 2004.

\section{B. Usulan Penatausahaan Hasil Hutan Di Hutan Rakyat}

Hutan hak/rakyat adalah hutan yang berada pada tanah yang dibebani hak atas tanah (UU No. 41/1999) atau hutan yang tumbuh pada tanah yang bukan kawasan hutan serta pemilikannya jelas. Pengelolaan dan pemanfaatan hutan rakyat oleh pemilik hak/rakyat apabila dilakukan secara benar dan baik, serta memperhatikan keadaan lingkungan bukan merupakan suatu ancaman terhadap ekosistem atau kelestarian alam, maka seyogyanya pemerintah tidak mempersulit dalam setiap pengurusan administrasi atau pengurusan lainnya yang berhubungan dengan pengelolaan dan pemanfaatan hutan rakyat. Jika memungkinkan pemerintah harus membantu agar perkembangan pembangunan hutan rakyat makin cepat sebagaimana diamanatkan pasal 17 ayat (3) PP No. 35 tahun 2002. Dengan demikian pemerintah berkewajiban memberikan insentif kepada pemilik lahan yang digunakan untuk hutan paling tidak senilai fungsi clean development yang diakibatkan pembangunan hutan itu setiap tahun. Disamping mempermudah proses administrasi pemanfaatan hasil hutan dari hutan rakyat, pemerintah juga memberikan pengarahan secara teknis atau memberikan penyuluhan agar lahan hak/milik yang tidak produktif dapat ditanami pepohonan.

Pasal 15, ayat (2), Peraturan Menteri Kehutanan No P.26/2005 menyatakan bahwa pemanfaatan hutan hak/rakyat yang berfungsi produksi dapat berupa :

a. Pemanfaatan hasil hutan kayu ;

b. Pemanfaatan hasil hutan bukan kayu ;

c. Pemanfaatan jasa lingkungan

Kemudian, pada pasal 16 dinyatakan bahwa tata cara pemanfaatan hutan hak diatur dengan peraturan Bupati/Walikota. Dalam Pasal 18 dinyatakan bahwa Pemerintah Kabupaten/Kota menetapkan lebih lanjut petunjuk pelaksanaan tentang pemanfaatan hutan hak dengan mengacu kepada peraturan perundang-undangan yang berlaku. Dasar acuan penatausahaan hasil hutan adalah SK Menteri Kehutanan Nomor 126/2003, akan tetapi dalam SK Menteri Kehutanan tersebut pasal-pasal mengenai penatausahaan hasil hutan di hutan rakyat belum secara rinci mengatur mengenai prosedur pelaksanaannya. Oleh karena itu untuk kelancaran pelaksanaan penatausahaan hasil hutan di hutan rakyat dipandang perlu untuk dibuatkan suatu acuan atau petunjuk pelaksanaannya. Petunjuk tersebut dimaksudkan sebagai dasar acuan dalam penertiban pemanfaatan hasil hutan di hutan rakyat, atau dengan perkataan lain merupakan dasar acuan pelaksanaan penatausahaan hasil hutan bagi pemerintah Kabupaten/Kota dan aparat pelaksana di lapangan dalam menyelenggarakan penatausahaan hutan rakyat.

Untuk lebih mengoptimalkan dalam pemanfaatan kayu rakyat oleh masyarakat dan untuk mempermudah dalam pemberian ijin pemanfaatan hutan rakyat, maka dalam pemanfaatan kayu rakyat dari hutan rakyat dikelompokan ke dalam dua (2) katagori, yaitu :

a. Pemanfaatan kayu rakyat untuk memenuhi kebutuhan kayu sendiri atau digunakan sendiri.

b. Pemanfaatan kayu rakyat untuk dikomersilkan atau diperjual belikan.

Untuk katagori kelompok pertama (a), yaitu kayu rakyat untuk keperluan sendiri, maka dalam pengurusan ijinnya cukup melaporkan kepada Kepala Desa dan tembusannya kepada KCDK atau UPTD Dinas Kehutanan setempat. Akan tetapi untuk memastikan bahwa kayu tersebut memang milik rakyat, dan penggunaannya benar-benar untuk memenuhi kebutuhan sendiri, maka dari pihak aparat baik aparat desa maupun dinas kehutanan Kabupaten/Kota melalui KCDK atau UPTD harus mengadakan pengecekan ke lapangan. Apabila kayu rakyat tersebut akan dimanfaatkan untuk tujuan komersil atau diperjual belikan (katagori b), maka dalam pemanfaatan kayu rakyat tersebut perlu diatur lebih lanjut oleh Dinas Kabupaten/Kota yang membidangi masalah Kehutanan, seperti dalam pembuatan Surat Ijin Penebangan (SIP), dokumen angkutan, dan lain sebagainya, namun dalam pelaksanaannya sebaiknya diserahkan kepada pemerintah daerah (Kepala Desa, Camat, KCDK atau UPTD Dinas Kehutanan setempat). Pemilik hutan rakyat tidak dibebani macam-macam surat yang harus diurus apalagi dengan macammacam biaya, akan tetapi setiap pelaksanaan pemanfaatan hasil hutan dari hutan rakyat (penebangan pohon) harus mempunyai Surat Ijin Penebangan (SIP) yang dikeluarkan oleh Dinas Kehutanan Kabupaten/Kota, melalui KCDK atau UPTD Dinas Kehutanan setempat, adapun dasar pertimbangan permohonan SIP harus melalui KCDK atau UPTD Dinas Kehutanan Kabupaten/Kota, dengan asumsi bahwa KCDK atau UPTD tersebut merupakan perwakilan dari Dinas Kehutanan Kabupaten/Kota yang 
berada di tingkat Kecamatan yang mengetahui tegakan kayu yang akan dimanfaatkan oleh masyarakat di seluruh wilayah Kabupaten/Kota, selain daripada itu di dalam upaya untuk menjaga dan atau memastikan bahwa kayu rakyat yang akan dimanfaatkan tersebut bukan berasal dari kawasan hutan milik negara.

Seperti yang telah diuraikan di atas, SK Menteri Kehutanan No 126/2003, belum mengatur secara rinci mengenai penatausahaan hasil hutan di hutan rakyat. Misalnya bagaimana caranya untuk memperoleh Surat Ijin Penebangan (SIP), penebangan kayu, pengangkutan kayu, dan lain sebagainya, untuk itu dalam rangka penertiban pemanfaatan hasil hutan di hutan rakyat dengan tujuan dikomersilkan atau diperjualbelikan, maka di pandang perlu untuk dibuatkan Petunjuk Pelaksanaannya atau Prosedur Pemanfaatannya, adalah sebagai berikut:

1. Petunjuk Pelaksanaan atau Prosedur Pemanfaatan Hasil Hutan (pengurusan SIP, penebangan, pengangkutan)

a. Pengurusan Surat Ijin Penebangan (SIP).

Pasal 33, ayat (1) SK Menteri Kehutanan No 126/2003 menyatakan bahwa setiap orang atau badan hukum yang memiliki hutan hak/rakyat yang akan melakukan penebangan pohon wajib melaporkan rencana penebangan kepada Kepala Desa setempat atau pejabat setara yang diangkat Kepala Dinas Provinsi dengan tembusan Kepada Kepala Dinas Kabupaten/Kota, kemudian pada ayat (2) Penyampaian rencana penebangan sebagaimana dimaksud pada ayat (1) dilengkapi dengan : a) Bukti kepemilikan hak atas tanah, b) Peta areal hutan hak/rakyat yang berisi letak, luas dan batas-batasnya diketahui oleh camat setempat, dan c) Potensi tegakan hutan hak/rakyat. Apabila kita melihat pada pasal 33 tersebut di atas, ketentuan tersebut baru mengatur mengenai rencana penebangan, akan tetapi sebenarnya dalam pemanfaatan hasil hutan yang berasal dari hutan rakyat masih banyak yang harus di atur atau harus di tata, seperti soal legalitas kayu rakyat, penebangan / produksi kayu rakyat, dokumen pengangkutan dan lain sebagainya. Intinya adalah administrasi pemanfaatan hasil hutan rakyat memang harus diatur agar hasil hutan yang diperoleh dan dimanfaatkan benar-benar berasal dari hutan milik rakyat dan selain daripada itu juga memperoleh manfaat yang optimal atas lahan hutan rakyat tersebut. Berkaitan dengan permohonan pembuatan ijin pemanfaatan hasil hutan dari hutan rakyat dan untuk lebih mempermudah dalam pengurusannya, maka sebagai gambaran di bawah digambarkan mengenai mekanisme permohonan penerbitan surat ijin penebangan (SIP) tersebut, adalah sebagai berikut :

- Mekanisme Pembuatan Surat Ijin Penebangan (SIP)

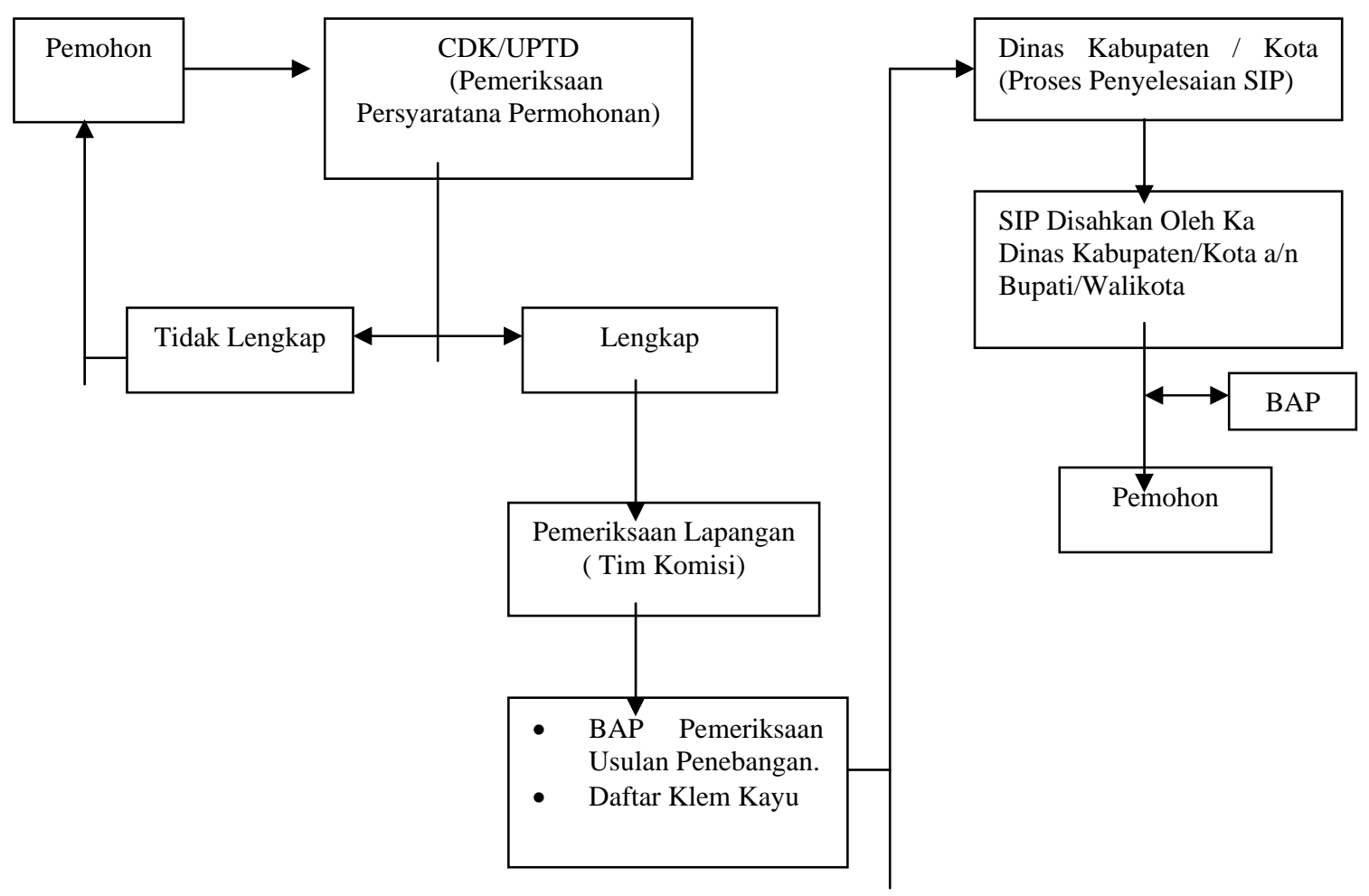


b. Legalitas Kayu Rakyat.

Berdasarkan Peraturan Menteri Kehutanan Nomor P.26/2005 pasal 17, ayat (1) yang menyatakan bahwa semua hasil hutan kayu dan bukan kayu yang berupa rotan dan gaharu dari areal hutan hak yang akan digunakan dan atau diangkut kedaerah lainya dilengkapi dengan Surat Keterangan Asal Usul (SKAU) yang diterbitkan oleh Kepala Desa atau pejabat yang setara.

Untuk lebih mengoptimalkan dalam penatausahaan hasil hutan umumnya dan khususnya di hutan rakyat, maka dalam upaya menjaga Kelestarian Hutan sesuai dengan PP No. 34 / 2002, pejabat yang berwenang dalam menerbitkan bukti kepemilikan kayu rakyat atau SKAU dalam hal ini adalah Kepala Desa atau pejabat yang setara diberikan pelatihan setingkat pejabat penerbit lainnya seperti P2LHP, P2SKSHH, P3HH dan kemudian diberikan sertifikat serta Surat Ijin Penerbitan SKAU, sedangkan untuk pengendalian dan pengawasan terhadap pejabat tersebut dilakukan oleh Dinas Kabupaten/Kota setempat yang membidangi kehutanan.

c. Prosedur penebangan pohon yang berasal dari hutan rakyat

Apabila kita lihat pada SK Menteri Kehutanan No. 126/2005, pasal 33 ayat (3) huruf (d), yaitu Kayu yang akan diterbitkan SKSHH untuk diangkut / dijual ke industri pengolahan kayu wajib dilakukan pengukuran oleh petugas kehutanan yang berkualifikasi Penguji Hasil Hutan $(\mathrm{PHH})$, dan kemudian dalam huruf (e), dinyatakan bahwa Hasil pemeriksaan dituangkan dalam Daftar Hasil Hutan dengan cap KR (DHH-KR), dengan prosedur sesuai dengan ketentuan yang berlaku dan ditanda tangani oleh petugas bersangkutan sebagai dasar penerbitan SKSHH oleh P2SKSHH. DHH-KR dibuat atas dasar hasil pemeriksaan yang dilakukan oleh Penguji Hasil Hutan (PHH), dan harus disahkan oleh petugas Kehutanan yang berkualitas Penguji Hasil Hutan $(\mathrm{PHH})$, dan ini merupakan dasar dalam permohohonan penerbitan SKSHH. Kemudian pada pasal 35, ayat (1) SK Menteri Kehutanan No. 126/2003, dinyatakan bahwa Pemilik hutan hak / rakyat termasuk pemilik kebun yang memanfaatkan kayu bulat dari land clearing wajib membuat dan melaporkan realisasi penebangan / pemanenan dan pengangkutan kayu bulat dengan menggunakan format blanko LMKB, dan kemudian pada ayat (2) dinyatakan bahwa laporan sebagaimana dimaksud pada ayat (1) disampaikan kepada Kepala Dinas Kabupaten/Kota dengan tembusan Kepala Dinas Provinsi.

Kalau kita lihat pada isi pasal-pasal tersebut di atas hanya mengatur apabila pohon tersebut sudah ditebang dan persyaratan yang harus dilengkapi apabila kayu tersebut akan diangkut, sebenarnya dalam pemanfaatan hasil hutan khususnya dalam penebangan kayu rakyat yang akan dikomersilkan atau diperjualbelikan, ada beberapa hal yang harus diperhatikan, seperti surat ijin penebangan (SIP), legalitas kayu, apakah sudah membayar kewajiban kepada pemerintah, dan lain sebagainya, intinya adalah dasar pemanfaatan kayu rakyat tersebut harus jelas. Untuk memberikan gambaran mengenai prosedur penebangan pohon dari hutan rakyat, di bawah digambarkan mengenai mekanisme pelaksanaan penebangan pohon dari hutan rakyat dan prosedur pengesahan LHP nya, adalah sebagai berikut:

- $\quad$ Mekanisme Pelaksanaan Penebangan Pohon dan Pengesahan LHP

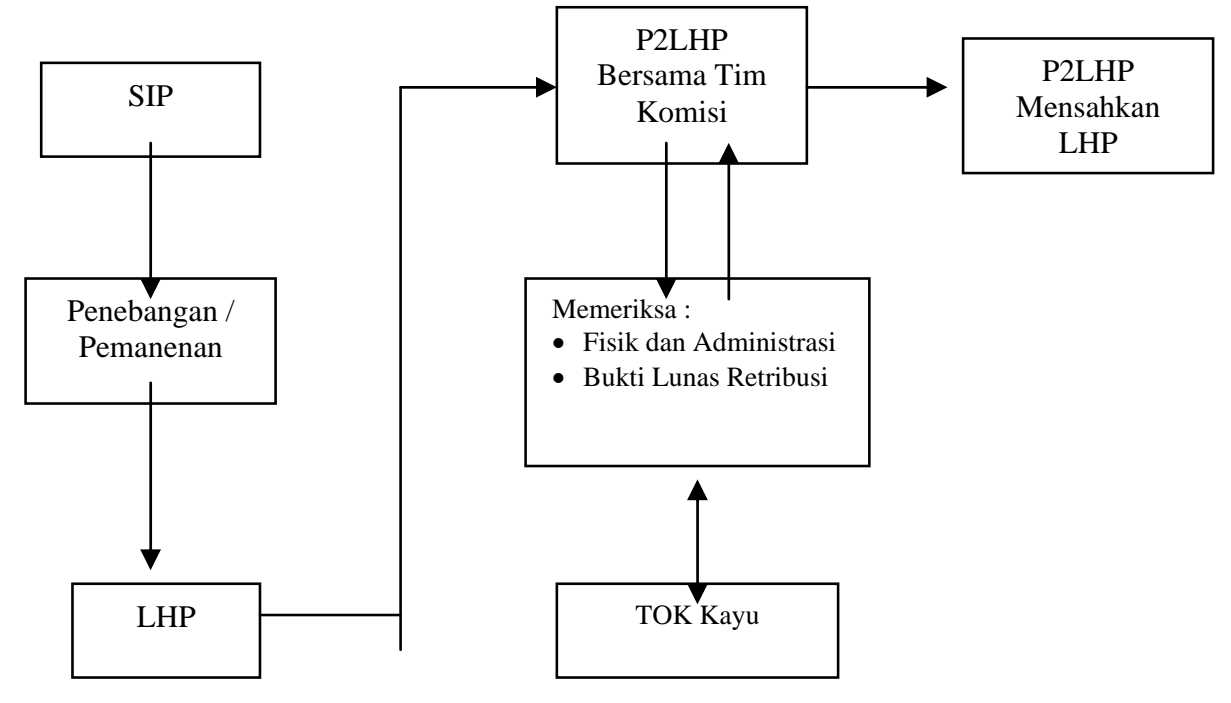


d. Prosedur pengangkutan hasil hutan yang berasal dari hutan rakyat.

Berdasarkan ketentuan teknis yang ada, bahwa setiap peredaran hasil hutan kayu rakyat wajib disertai dokumen pengangkutan, dan sesuai dengan pasal 16 ayat (1) SK Menteri Kehutanan No 126/2003, yang menyatakan bahwa : Setiap pengangkutan hasil hutan kayu dari lokasi penebangan/pemanenan di tempat tebangan atau dari TPn yang akan di angkut ke TPk hutan wajib menggunakan Daftar Pengangkutan (DP), yang diterbitkan oleh Petugas Perusahaan Pemegang IUPHHK, IPHHK atau ILS dengan menggunakan blanko model DK. A. 202, kemudian dalam ayat (2) Daftar Pengangkutan dimaksud pada ayat (1) berfungsi sebagai dokumen pengangkutan antara dan bukti keabsahan hasil hutan. Untuk dimasa yang akan datang dalam pengangkutan kayu rakyat akan diberlakukan dokumen angkutan lain selain SKSHH yang di cap KR, yaitu Surat Keterangan Asal Usul (SKAU) sebagai dokumen angkutan kayu rakyat resmi yang diterbitkan oleh Kepala Desa/Lurah atau pejabat yang setara, sesuai dengan Peraturan Menteri Kehutanan Nomor P.51/Menhut-II/2006, akan tetapi dalam Permenhut tersebut pada pasal (4), huruf (a), jenis kayu yang akan diangkut masih terbatas pada 3 (tiga) jenis kayu saja, yaitu kayu sengon, kayu karet, dan kayu kelapa, sedangkan untuk jenis kayu lainnya akan ditetapkan oleh Menteri Kehutanan atas dasar usulan dari masing-masing Dinas Provinsi berdasarkan hasil inventarisasi jenis, potensi dan lokasi penyebaran kayu (pasal (4), huruf (b) Permenhut No P.51/2006).

Sesuai dengan pasal 11, ayat (2) Permenhut No 51/2006 menyatakan bahwa Dengan ditetapkan peraturan ini, maka ketentuan Pasal 33, Pasal 34, dan Pasal 35 Keputusan Menteri Kehutanan Nomor 126/Kpts-II/2003, dinyatakan tetap berlaku untuk jenis-jenis kayu diluar jenis-jenis kayu yang ditetapkan sebagaimana dimaksud pada pasal 4 dalam peraturan ini. Sehubungan dengan pasal tersebut di atas, maka untuk jenis kayu diluar sengon, karet, dan kelapa (pasal 4, huruf (a), Permenhut No. P.51 / 2006), dokumen pengangkutannya masih menggunakan SKSHH yang di cap kayu rakyat dan prosedur penerbitannya sesuai dengan Permenhut No. P.18/2005. Sebagai dasar untuk penerbitan dokumen angkutan pemilik kayu wajib mengajukan permohonan kepada pejabat yang berwenang menerbitkan dokumen angkutan, atas rencana hasil hutan yang akan diangkut, wajib dibuatkan Daftar Hasil Hutan (DHH) kayu rakyat sebagai dasar dalam mengajukan permohonan penerbitan dokumen angkutan kepada pejabat yang berwenang. Atas dasar permohonan penerbitan SKSHH yang diajukan, pejabat yang ditunjuk wajib melakukan pemeriksaan atas kebenaran fisik hasil hutan yang akan diangkut tersebut sesuai dengan prosedur yang telah ditetapkan dan apabila hasil pemeriksaan fisik dan administrasi sudah sesuai, maka pejabat P2SKSHH, menandatangani DHH dan menerbitkan SKSHH Kayu Rakyat. Atas SKSHH yang sudah diterbitkan maka SKSHH tersebut diberikan pada pejabat struktural di Dinas Kabupaten / Kota setempat untuk diketahui dan disetujui. Pernyataan diketahui dan disetujui oleh pejabat eselon III di Dinas Kabupaten/Kota menimbulkan pertentangan baik oleh Pejabat yang menanda-tangani SKSHH tersebut, maupun pemohon / pengguna SKSHH itu sendiri, alasannya adalah :

a. Jarak antara Pejabat eselon III yang menandatangani untuk mengetahui dan menyetujui SKSHH dengan fisik kayu yang akan diangkut tidak selamanya dapat dijangkau dengan mudah, sehingga dalam pelaksanaanya sulit untuk dilakukan oleh pejabat tersebut yang mempunyai tugas-tugas rutin dan padat.

b. Pemohon penerbitan SKSHH tidak hanya dari satu daerah saja, akan tetapi dari beberapa daerah yang masih dalam satu wilayah Dinas Kehutanan Kabupaten/Kota setempat, sehingga dalam pelaksanaan pengecekan fisik yang dilakukan oleh pejabat tersebut tidak mungkin dilakukan secara bersamaan.

c. Untuk pengurusan penerbitan SKSHH membutuhkan waktu yang cukup lama, sementara kayu tersebut harus dikirim secepatnya, karena perusahaan terikat oleh kontrak kerja antara penjual dan pembeli yang harus dipenuhi agar tidak mendapat sanksi kerja.

d. Blanko SKSHH tidak selalu tersedia, untuk permohonan blanko saja memerlukan waktu yang lama, karena pendistribusian blanko dilakukan oleh Dinas Provinsi, sedangkan yang mencetak blanko SKSHH tersebut adalah Dirjen BPK. Adapun pemberian blanko kepada pemohon SKSHH berdasarkan kebutuhan yang dimintakan oleh perusahaan melalui P2SKSHH, dan untuk permohonan blanko tersebut tidaklah mudah, serta dalam pengurusannya lebih dari 1 (satu) hari. 
Apabila dilihat dari tujuan penatausahaan hasil hutan dalam pembuatan dokumen pengangkutan hasil hutan seperti yang tertulis di atas, sangatlah baik, intinya adalah harus ada fungsi kontrol terhadap pejabat P2SKSHH, agar tidak menyalahgunakan wewenang dan tanggung jawab yang dimilikinya, ini dilakukan mengingat tempat kedudukan mereka jauh dari ibukota Kabupaten/Kota, maka dengan dilibatkannya pejabat eselon III untuk mengetahui dan menyetujui penerbitan SKSHH diharapkan tidak akan terjadi penyimpangan wewenang, akan tetapi dengan dilibatkannya eselon III untuk mengetahui dan menyetujui persoalannya menjadi lain, yang berdampak kepada pengangkutan hasil hutan tidak efektif, yang banyak dikeluhkan oleh pemohon SKSHH maupun pejabat eselon itu sendiri. Sebagai bahan pertimbangan lebih lanjut untuk adanya fungsi kontrol terhadap pejabat P2SKSHH, pejabat yang mengetahui dan menyetujui SKSHH tersebut eselonnya diturunkan dari eselon III menjadi eselon IV, dan berkedudukan dekat dengan pejabat P2SKSHH, seperti KCDK, Ka BKPH, atau Petugas yang di tunjuk langsung oleh Dinas Kehutanan Provinsi, dengan rekomendasi dari Dinas Kehutanan Kabupaten/Kota setempat.

Guna memperlancar mobilitas peredaran kayu rakyat antar desa dan atau antar kecamatan yang masih dalam wilayah Kabupaten / Kota yang belum berpindah kepemilikan, maka atas hasil hutan kayu rakyat tersebut dapat dilampiri dengan dokumen resmi lainnya. Dokumen resmi lainnya dimaksudkan di atur lebih lanjut oleh pemerintah Kabupaten/Kota atas dasar rekomendasi dari Dinas Kehutanan Provinsi, dengan memperhatikan faktor kemudahan bagi proses pelayanan, dapat dipertanggung jawabkan dan bermanfaat bagi aspek pengendalian produksi/peredaran kayu rakyat, sehingga memudahkan untuk kepentingan penelusuran lacak balak, sesuai dengan Peraturan Menteri Kehutanan Nomor P.18/2005, Pasal 20, ayat (6). Dokumen angkutan (SKSHH) Kayu Rakyat dapat diterbitkan oleh P2SKSHH apabila LMKB diketahui oleh $\mathrm{P} 3 \mathrm{HH}$ (P3KB dan P3KO).

- $\quad$ Mekanisme Pengangkutan Hasil Hutan

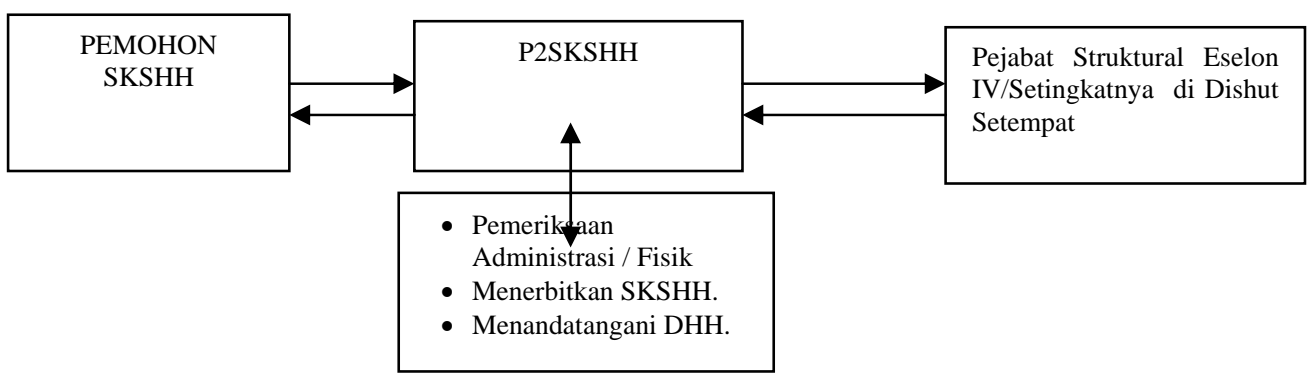

2. Mekanisme Penatausahaan Kayu Rakyat

Apabila diilustrasikan alur atau mekanisme penatausahaan hasil hutan di hutan rakyat, adalah sebagai berikut : 


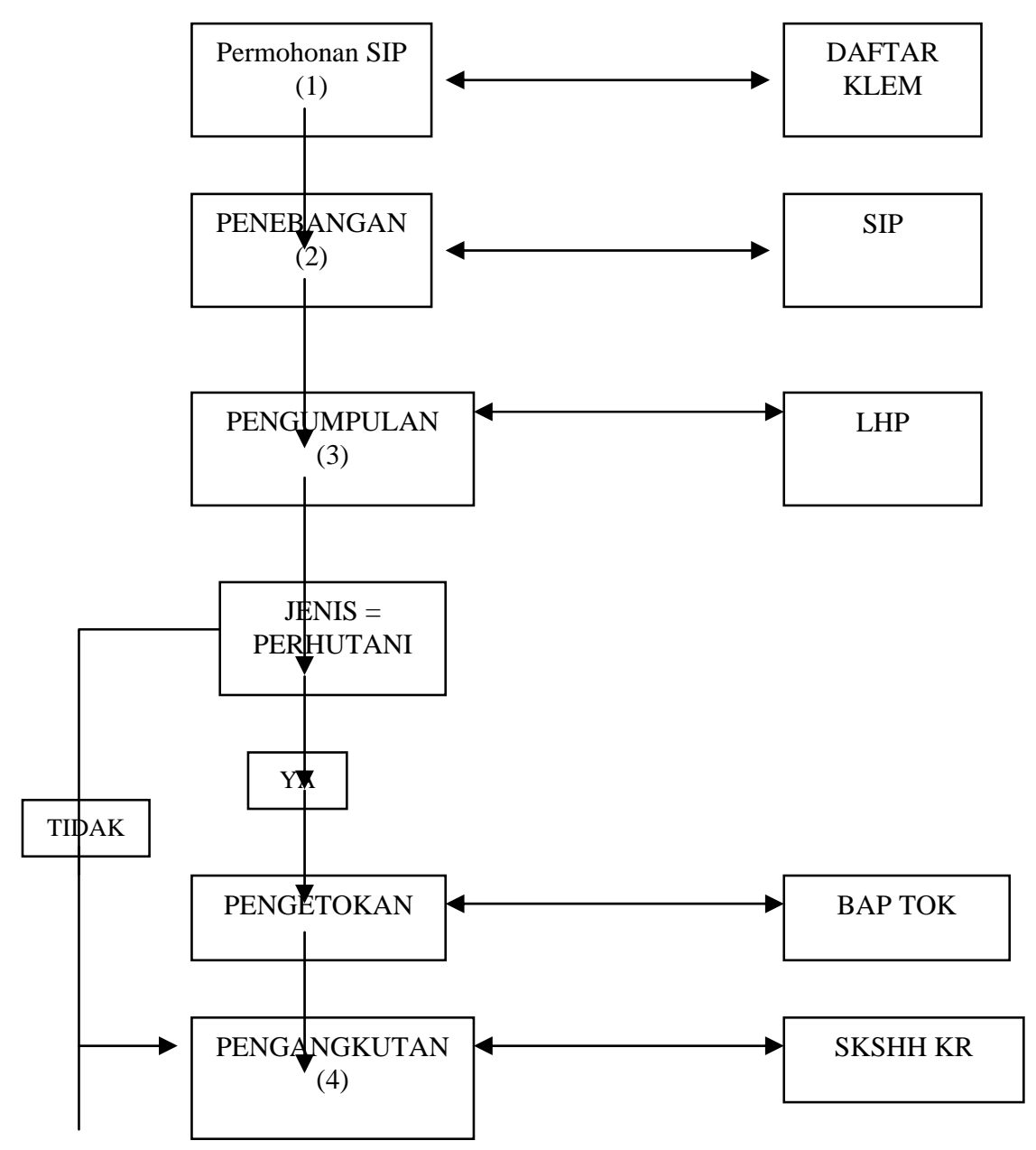

\section{KETERANGAN :}

1 Permohonan Surat Ijin Penebangan (SIP).

$>$ Pemohon mengajukan surat permohonan ijin penebangan

$>$ Pemeriksaan lapangan oleh Tim Komisi

$>$ Pembayaran Retribusi

> Penerbitan Surat Ijin Penebangan oleh Kepala Dinas Kehutanan Kabupaten/Kota a/n Bupati/Walikota

2 Penebangan Kayu

$>$ Berdasarkan SIP, pemohon melaksanakan penebangan atas hasil hutan yang dimilikinya

> Pemilik kayu, setelah melaksanakan penebangan/pemanenan dan pembagian batang/pemotongan, wajib melakukan pengukuran dan penandaan batang sesuai ketentuan berlaku.

> Setelah dilakukan pengukuran dan penandaan batang, atas kayu-kayu tersebut dibukukan dalam Buku Ukur atau LHP.

3 Pengumpulan kayu

Pemilik membuat Laporan Hasil Produksi (LHP) kayu yang telah ditebang.

$>$ Membayar retribusi sesuai dengan ketentuan yang berlaku. 
Pemeriksaan LHP oleh unsur Cabang Dinas Kabupaten/Kota dan (khusus di P. Jawa) Perum Perhutani.

$>$ Jenis kayu yang sama atau dibudidayakan oleh Perum Perhutani, di beri tanda atau di TOK kayu.

> Pemberian tanda TOK dilakukan oleh petugas pemegang palu Tok dari Dinas Kabupaten/Kota dengan disaksikan oleh unsur Cabang Dinas, Perum Perhutani (di P. Jawa) dan Pemilik Kayu.

LHP disahkan.

4 Pengangkutan Kayu

> Atas dasar LHP yang sudah disahkan, pemilik kayu membuat permohonan dokumen pengangkutan atau membuat permohonan penerbitan SKSHH kayu rakyat.

$>$ Untuk kayu dari hutan rakyat, dokumen angkutannya menggunakan blanko SKSHH yang diberi cap Kayu Rakyat.

$>$ Permohonan penerbitan SKSHH ditujukan kepada P2SKSHH dan tembusannya disampaikan kepada Kepala Dinas Kabupaten/Kota setempat yang menangani masalah kehutanan.

\section{KESIMPULAN DAN SARAN}

\section{A. Kesimpulan}

1 Penatausahaan hasil hutan di hutan rakyat belum secara rinci diatur dalam perundang-undangan.

2 Prosedur / tata cara pemanfaatan hasil hutan di hutan rakyat belum jelas.

3 Hutan rakyat mempunyai fungsi yang penting bagi pembangunan nasional akan tetapi belum tertata dengan baik.

4 Hasil hutan rakyat mempunyai potensi dan kontribusi yang besar dalam pemenuhan kebutuhan bahan baku industri pengolahan kayu di Indonesia.

\section{B. Saran}

1 Penatausahaan hasil hutan di hutan rakyat masih perlu untuk disempurnakan, dalam rangka perbaikan pelayanan publik terhadap pengolahan hutan agar pengolahan hutan dapat lebih efisien, efektif, dan lestari.

2 Perlu dibuatkan aturan atau petunjuk pelaksanaan (juklak) dan atau petunjuk teknis (juknis) dari sistim penatausahaan hasil hutan di hutan rakyat agar tercipta penyelenggaraan hasil hutan rakyat, tertib lancar, efisien dan bertanggung jawab sesuai dengan potensi yang dimiliki.

3 Untuk pengangkutan hasil hutan rakyat tidak perlu menggunakan SKSHH yang memerlukan biaya pembuatan dan pengurusan yang cukup besar, akan tetapi cukup dengan daftar klem kayu atau LHP yang sudah disahkan oleh Tim Komisi yang beranggotakan : a. Unsur Cabang Dinas Kehutanan Kabupaten/Kota setempat, b. Unsur Kecamatan, c. Unsur Desa, d. (Khusus di P. Jawa) Unsur Perum Perhutani.

\section{DAFTAR PUSTAKA}

Keputusan Direktur Jenderal Pengusahaan Hutan No.521/Kpts/IV-Tib/1985, tanggal 4 Desember 1985. Tentang Petunjuk Teknis Tata Usaha Kayu. Departemen Kehutanan, Jakarta.

Keputusan Menteri Kehutanan No.402/Kpts-IV/1990, tanggal 7 Agustus 1990. Tentang Tata Usaha Kayu. Departement Kehutanan, Jakarta.

Undang-undang Nomor 41 Tahun 1999, tanggal 30 September 1999. Tentang Kehutanan, Jakarta.

Keputusan Menteri Kehutanan dan Perkebunan No. 316/Kpts-II/1999, tanggal 7 Mei 1999. Tentang Tata Usaha Hasil Hutan. Departemen Kehutanan dan Perkebunan, Jakarta.

Keputusan Menteri Kehutanan No.126/Kpts-II/2003, tanggal 4 April 2003. Tentang Penatausahaan Hasil Hutan. Departemen Kehutanan, Jakarta.

Peraturan Pemerintah No.34 Tahun 2002, tanggal 8 Juni 2002. Tentang Tata Hutan dan Penyusunan Rencana Pengelolaan Hutan dan Penggunaan Kawasan Hutan. Departemen Kehutanan, Jakarta.

Peraturan Pemerintah No.35 Tahun 2002, tanggal 8 Juni 2002. Tentang Dana Reboisasi. Departemen Kehutanan, Jakarta. 
Peraturan Menteri Kehutanan No.P.18/Menhut-II/2005, tanggal 13 Juli 2005. Tentang Perubahan Ketiga SK Menteri Kehutanan No. 126/Kpts-II/2003, Tentang Penatausahaan Hasil Hutan. Departemen Kehutanan, Jakarta.

Peraturan Menteri Kehutanan No.P.26/Menhut-II/2005, tanggal 6 Agustus 2005. Tentang Pedoman Pemanfaatan Hutan Hak. Departemen Kehutanan, Jakarta.

Peraturan Menteri Kehutanan No.P.51/Menhut-II/2006, tanggal 10 Juli 2006. Tentang Penggunaan Surat Keterangan Asal Usul (SKAU) Untuk Pengangkutan Hasil Hutan Kayu Yang Berasal Dari Hutan Hak.. Departemen Kehutanan, Jakarta. 